\section{Response to: 'Adipose stromal vascular fraction and regenerative therapy in SSc: response to the article by Magalon et al' by De Benedetto et al}

We would like to thank Di Benedetto et al ${ }^{1}$ for their constructive comments on our recent publication in Annals of Rheumatic Disease entitled 'Molecular profile and proangiogenic activity of the adipose-derived stromal vascular fraction used as an autologous innovative medicinal product in patients with systemic sclerosis'. ${ }^{2}$

Di Benedetto et al mentioned that the profibrotic signature of mesenchymal stem cells (MSCs) derived from patients with the diffuse cutaneous form of systemic sclerosis (dc-SSc) has been established from previous works. In line with this, they discussed the potential risk of increasing the fibrotic burden by using autologous adipose-derived stromal vascular fraction (ADVSF) in which MSCs are highly represented.

Although this is a fair question in the context of developing MSCs-based therapy for SSc, we would like to emphasise the fact that the biological findings referred to by Di Benedetto et al, may not be fully extrapolated to the ADSVF used in our study. Indeed, the mentioned studies rather relate to MSCs derived in culture from the bone marrow using research-grade reagents that are very different from the mesenchymal cell compartment that we aimed to describe in the non-cultured clinical-grade ADSVF. Indeed, the use of MSCs necessitate an in vitro amplification procedure which can have a major impact on the differentiation and characteristics of MSCs, ${ }^{34}$ thereby limiting the comparison between native MSCs present within ADSVF. ADSVF is also a complex product whose biological properties result from multiple interactions between various cell subpopulations, and the role of each cell subset remains to be identified. In addition, it is well established that cultured MSCs derived from bone marrow and adipose tissue are quite different populations ${ }^{5}$ and to our knowledge, such a profibrotic profile of MSCs derived from the adipose tissue of patients with SSc was not reported, as recently confirmed by the review from Rozier et $a l .{ }^{6}$ In 2017, report from the team of the Department of Biotechnological and Applied Clinical Sciences (l'Aquila University, Italy) indicated that MSCs isolated from adipose tissue of dc-SSc may represent a possible therapeutic option as they show similar biological properties compared with MSCs from healthy donors. ${ }^{7}$

From a clinical point of view, we are surprised that Benedetto et al omitted to mention that autologous ADSVF, injected in the fingers of 12 patients with SSc (including five dc-SSc) displaying hand disability, was shown to have a good safety profile and a potential efficacy. ${ }^{8}$ In particular, results of Rodnan score applied to the hands, with a follow-up until 2 years, did not indicate any worsening of the fibrosis aspect. ${ }^{9}$

We would also like to emphasise that the potential strength of our study was that it was performed on clinical-grade ADSVF, meaning that the analysed ADSVF correspond to the products potentially injected in the SCLERADEC II randomised placebo-controlled trial (NCT02558543). From our point of view, evaluation of this therapeutic ADSVF makes our findings of particular clinical relevance but limits the amount of ADSVF available for biological investigations. This is the reason why functional angiogenic assays could not be performed on a larger number of samples prepared from various forms of the disease. We fully agree that additional studies are needed to consider whether the limited or diffuse cutaneous form of SSc have a similar impact on ADSVF properties. As suggested by Benedetto et al, refinements in the characterisation of SSc-ADSVF profile is still required. Beyond transcriptomic and phenotypic signature, further work should implement accurate in vitro and in vivo functional assays to address the contribution of each of the cellular subsets and their interactive benefit in the modulation of fibrosis, angiogenesis and inflammation. These targeted approaches, together with outputs from the ongoing clinical trials, are needed to further define the optimal strategies for cell-based therapies of SSc.

\section{Jérémy Magalon $\circledast_{1}^{1,2}$ Mélanie Velier, ${ }^{1,2}$ Stéphanie Simoncini, ${ }^{2}$ Françoise Dignat-George, ${ }^{2}$ Brigitte Granel, ${ }^{2,3}$ Pascale Paul, ${ }^{1,2}$ Florence Sabatier ${ }^{1,2}$ \\ ${ }^{1}$ Cell Therapy Department, Hôpital de la Conception, Marseille, France ${ }^{2}$ Aix Marseille University, Marseille, France \\ ${ }^{3}$ Internal Medicine Department, Hôpital Nord, Marseille, France}

Correspondence to Professor Florence Sabatier, Cell Therapy Department, Hôpital de la Conception, Assistance Publique Hôpitaux de Marseille, Marseille 13005 , France; florence.sabatier@ap-hm.fr

Handling editor Josef S Smolen

Contributors Drafting of the manuscript:JM, MV, SS. Critical revision of the manuscript for important intellectual content: FDG, BG, PP and FS.

Competing interests None declared.

Patient consent for publication Not required.

Provenance and peer review Commissioned; internally peer reviewed.

(C) Author(s) (or their employer(s)) 2020. No commercial re-use. See rights and permissions. Published by BMJ.

\section{Check for updates}

To cite Magalon J, Velier M, Simoncini S, et al. Ann Rheum Dis 2020;79:e54.

Received 4 February 2019

Revised 5 February 2019

Accepted 5 February 2019

Published Online First 20 February 2019

\section{(5) Linked}

- https://doi.org/10.1136/annrheumdis-2019-215113

Ann Rheum Dis 2020;79:e54. doi:10.1136/annrheumdis-2019-215132

\section{ORCID iD}

Jérémy Magalon http://orcid.org/0000-0003-1494-7011

\section{REFERENCES}

1 Di Benedetto P, Cipriani P, Ruscitti P, et al. Adipose stromal vascular fraction and regenerative therapy in SSc: response to the article by Magalon et al. Ann Rheum Dis 2020;79:e53.

2 Magalon J, Velier M, Simoncini S, et al. Molecular profile and proangiogenic activity of the adipose-derived stromal vascular fraction used as an autologous innovative medicinal product in patients with systemic sclerosis. Ann Rheum Dis 2019;78:391-8.

3 Hagmann S, Moradi B, Frank S, et al. Different culture media affect growth characteristics, surface marker distribution and chondrogenic differentiation of human bone marrow-derived mesenchymal stromal cells. BMC Musculoskelet Disord 2013:14.

4 Guimarães-Camboa N, Cattaneo P, Sun Y, et al. Pericytes of Multiple Organs Do Not Behave as Mesenchymal Stem Cells In Vivo. Cell Stem Cell 2017:20:345-59.

5 Noël D, Caton D, Roche S, et al. Cell specific differences between human adiposederived and mesenchymal-stromal cells despite similar differentiation potentials. Exp Cell Res 2008;314:1575-84.

6 Rozier P, Maria A, Goulabchand R, et al. Mesenchymal stem cells in systemic sclerosis: allogenic or autologous approaches for therapeutic use? Front Immunol 2018;9.

7 Capelli C, Zaccara E, Cipriani P, et al. Phenotypical and functional characteristics of in Vitro-Expanded adipose-derived mesenchymal stromal cells from patients with systematic sclerosis. Cell Transplant 2017:26:841-54.

8 Granel B, Daumas A, Jouve E, et al. Safety, tolerability and potential efficacy of injection of autologous adipose-derived stromal vascular fraction in the fingers of patients with systemic sclerosis: an open-label phase I trial. Ann Rheum Dis 2015;74:2175-82

9 Daumas A, Magalon J, Jouve E, et al. Long-term follow-up after autologous adiposederived stromal vascular fraction injection into fingers in systemic sclerosis patients. Curr Res Trans/ Med 2017:65:40-3. 